\title{
Modeling and Investigation of the Swelling Kinetics of Acrylamide-Sodium Acrylate Hydrogel
}

\author{
Azmi Seyhun Kipcak, Osman Ismail, Ibrahim Doymaz, and Sabriye Piskin \\ Department of Chemical Engineering, Faculty of Chemical and Metallurgical Engineering, Yildiz Technical University, \\ Davutpasa Campus, Davutpasa Street No. 127, Esenler, 34210 Istanbul, Turkey
}

Correspondence should be addressed to Azmi Seyhun Kipcak; seyhunkipcak@gmail.com

Received 17 May 2014; Accepted 9 July 2014; Published 13 August 2014

Academic Editor: Nurettin Sahiner

Copyright (C) 2014 Azmi Seyhun Kipcak et al. This is an open access article distributed under the Creative Commons Attribution License, which permits unrestricted use, distribution, and reproduction in any medium, provided the original work is properly cited.

\begin{abstract}
The acrylamide-sodium acrylate hydrogel was synthesized by free radical polymerization of the method of solution polymerization. Dynamic swelling tests were conducted at 25,40 , and $60^{\circ} \mathrm{C}$ temperatures, in order to investigate the swelling properties of the synthesized hydrogel. The results have shown that swelling content and swelling rate of the hydrogel increase with increasing the swelling water temperature. The diffusivity values changed from $1.81 \times 10^{-7}$ to $2.97 \times 10^{-7} \mathrm{~m}^{2} \mathrm{~s}^{-1}$ over the temperature range. The activation energies were found as $3.56,3.71$, and $3.86 \mathrm{~kJ} \mathrm{~mol}^{-1}$ at 25,40 , and $60^{\circ} \mathrm{C}$, respectively. The experimental drying curves obtained were fitted to a three different models, namely, Peleg's, first-order absorption kinetic, and exponential association equation models. All the models applied provided a good agreement with the experimental data with high values of the coefficient of determination $\left(R^{2}\right)$, the least values of the reduced chi-square $\left(\chi^{2}\right)$, and root mean square error (RMSE). Comparing the determination of coefficient, reduced chi-square, and root mean square error values of three models, it was concluded that the exponential association equation model represents swelling characteristics better than the others.
\end{abstract}

\section{Introduction}

Hydrogels are rigid, hydrophilic macromolecules which can absorb minimum $20 \%$ water of their weight. Hydrogels are known as hydrophilic network structured polymers having hydrophilic functional groups such as hydroxyl, carboxylic acid, and amines. Hydrogels can swell within a period of time in the appropriate solvents. This type of cross-linked polymer swollen state hydrogels is called "gel." Due to their hydrophilic properties hydrogels can absorb significant amounts of water and are characterized as their nonsolubility properties. They can swell to an equilibrium value without losing its shape $[1,2]$.

Due to the mentioned properties of hydrogels a very wide range of application areas are present, such as high swelling capacity and lack of toxicity and biocompatibility; these hydrogels are used for many applications including disposable diapers, absorbent pads, controlled release fertilizers in agricultural areas, water blocking tapes, feminine napkins, separation processes, controlled drug delivery systems, space technology, and extraction of precious metals [3-7].

The $\mathrm{pH}$ and temperature-sensitive hydrogels are being used for various applications including controlled drug delivery system and immobilized enzyme systems. According to the literature, swelling and deswelling behavior of the gels were affected by the temperature, solvent composition, electric field, ionic strength, and $\mathrm{pH}$ [8-11].

Heat-swellable hydrogels can be synthesized by using hydrophilic monomers such as AAm, AA, and MAA. Besides thermal contractible hydrogels can be synthesized by using $\mathrm{N}$-methylacrylamide and $\mathrm{N}, \mathrm{N}$-dimethylacrylamide monomers [12].

In temperature-sensitive hydrogels at least one of the components forming the polymer system in the solvent medium (usually water) must have a temperature-dependent solubility. In order to obtain a temperature-sensitive hydrogel showing a marked change in the degree of swelling in water, the components must be insoluble below or above 
a certain temperature. This volume change observed in the temperature of the polymer chain components of the hydrogel is reversible depending on the degree of ionization. Temperature sensitive hydrogels exhibit a "lower critical solution temperature" (LCST) behavior. Below the LCST, these hydrogels are swollen in water. As the temperature is increased above LCST, it undergoes abrupt changes in volume and shrinks quickly $[13,14]$.

In all the above applications, the amount of water absorption and retention properties is most important. High swelling rate is an important property of hydrogels. They mainly need several hours to reach maximum absorption capacity. The slow swelling of dried hydrogels is due to the slow diffusion of water into the glassy matrix of the dried hydrogels [15-17]. Poly(acrylamide) (PAAm) is an important and hydrophilic polymer for preparation of hydrogels [18]. For this reason, in recent years by researchers, several studies were conducted in order to modify the chemical and physical properties of $\mathrm{P}(\mathrm{AAM})$. In the preparation of acrylamidebased hydrogels, there are a number of studies containing sodium acrylate, crotonic acid, maleic acid, and so forth used as hydrophilic monomers $[19,20]$.

The kinetics of swelling and shrinking of gels is theoretically generalized and experimentally studied. A new relation, in addition to the differential equation developed by Tanaka et al., is formulated to solve the kinetics of gels having arbitrary shape. Using new theory, they provided explicit solutions for long cylinder and large disk gels [21, 22].

In the literature Tanaka and Filmore [21] constructed a kinetic model of the absorbent gels swelling. After this study Li and Tanaka [22] added new approaches about the swelling and shrinking of gels which were then implemented by many researchers $[23,24]$.

In this study, the acrylamide-sodium acrylate hydrogel was synthesized. The swelling characteristics (swelling content, swelling rate, diffusion of water, and activation energy) of hydrogels were investigated based on the swelling values obtained at different temperatures. In the literature, several researches and models were conducted about the absorbent gels swelling kinetics. As an alternative to these models, three different models, which were never used in this study field, are used for the swelling characteristics. These mentioned models are Peleg, exponential association equation model, and first-order absorption kinetic model. Using these models, best fitted model for the swelling kinetics was determined from the experimental data.

\section{Materials and Methods}

2.1. Materials. Acrylamide (AAm) was purchased from Merck, Schuchardt, Germany, and used as a monomer. The N,N'-methylenebisacrylamide (MBA, Fluka, analytical grade) was used as cross-linking agent. The redox initiator system that comprised ammonium per sulfate initiator (APS, Merck, Darmstadt, Germany, analytical grade) and the activator N,N,N',N' -tetramethylethylenediamine (TMEDA) were supplied by Merck (Schuchardt, analytical grade). Methanol (MeOH, BDH, commercial grade) was used as a dehydrating agent against the water inside the gel. Sodium acrylate $\left(\mathrm{C}_{3} \mathrm{H}_{3} \mathrm{NaO}_{2}\right)$ was synthesized in the laboratory. In the experiments, a digital balance of model BB3000 MetlerToledo (Switzerland), a vacuum oven of model BINDER (Tuttlingen, Germany), and Heidolph MR Hei-Standart (Germany) magnetic stirrer with heater were used.

2.2. Preparation of the Sodium Acrylate. Sodium hydroxide $(0.5$ moles of $\mathrm{NaOH})$ solution was prepared using distilled water. Then the solution was taken in a conical flask in dry ether and titrated with 0.1 mole of acrylic acid $\left(\mathrm{C}_{3} \mathrm{H}_{4} \mathrm{O}_{2}\right)$. After the titration process a white solid was separated out, filtered under a vacuum pump, and dried in a vacuum desiccator. The formation scheme of the sodium acrylate is shown as follows [25]:

$$
\begin{aligned}
\mathrm{CH}_{2} & =\mathrm{CHCOOH}+\mathrm{NaOH} \longrightarrow \mathrm{CH}_{2} \\
& =\mathrm{CHCOONa}+\mathrm{H}_{2} \mathrm{O} .
\end{aligned}
$$

2.3. Synthesis of Cross-linked (AAm/SA) Hydrogel. In this study, cross-linked acrylamide-sodium acrylate hydrogel was synthesized by free radical solution polymerization of AAm monomer in aqueous solution. A series of hydrogels were prepared by the following procedure.

MBA were used for cross-linkers in the hydrogel synthesis. For the synthesis of AAm/SA hydrogel, after many preexperiments also from the study of Ismail et al. [26], the synthesis procedure was determined. According to the procedure, $1 \mathrm{~g}$ of AAm monomer and $80 \mathrm{mg}$ SA were dissolved in $8 \mathrm{~mL}$ distilled water; then $0.0777 \mathrm{mmol}$ of $\mathrm{MBA}$ was added, which is $1 \%$ of the monomer. $1 \mathrm{~mL} / 0.219 \mathrm{mmol}$ APS was added from the $5 \mathrm{~g} / 100 \mathrm{~mL}$ APS solution and $1 \mathrm{~mL} / 0.086 \mathrm{mmol}$ TMEDA was added from the 1\% TMEDA solution. The prepared solution was poured into a 3-mmdiameter glass tube and held for the gelling process with nitrogen medium.

Synthesized hydrogel was removed from the glass tube and put into distilled water for the washing process. After the washing process, the hydrogel was dried firstly at room temperature and then in the vacuum oven at a temperature of $40^{\circ} \mathrm{C}$.

The formation scheme of the hydrogel is given in Figure 1.

2.4. Swelling Content. The quantitative figures of swelling content were calculated as follows:

$$
S=\frac{w_{s}-w_{d}}{w_{d}}
$$

where $S$ is the swelling content (g/g d.b), $w_{s}$ is weight of the swollen hydrogel at time $t$, and $w_{d}$ is the weight of the original dry hydrogel.

2.5. Swelling Rate. Change in swelling content per unit of time in hydrogels is called "swelling rate" of the hydrogel and is calculated using

$$
S_{R}=\frac{S_{t+\Delta t}-S_{t}}{\Delta t}
$$




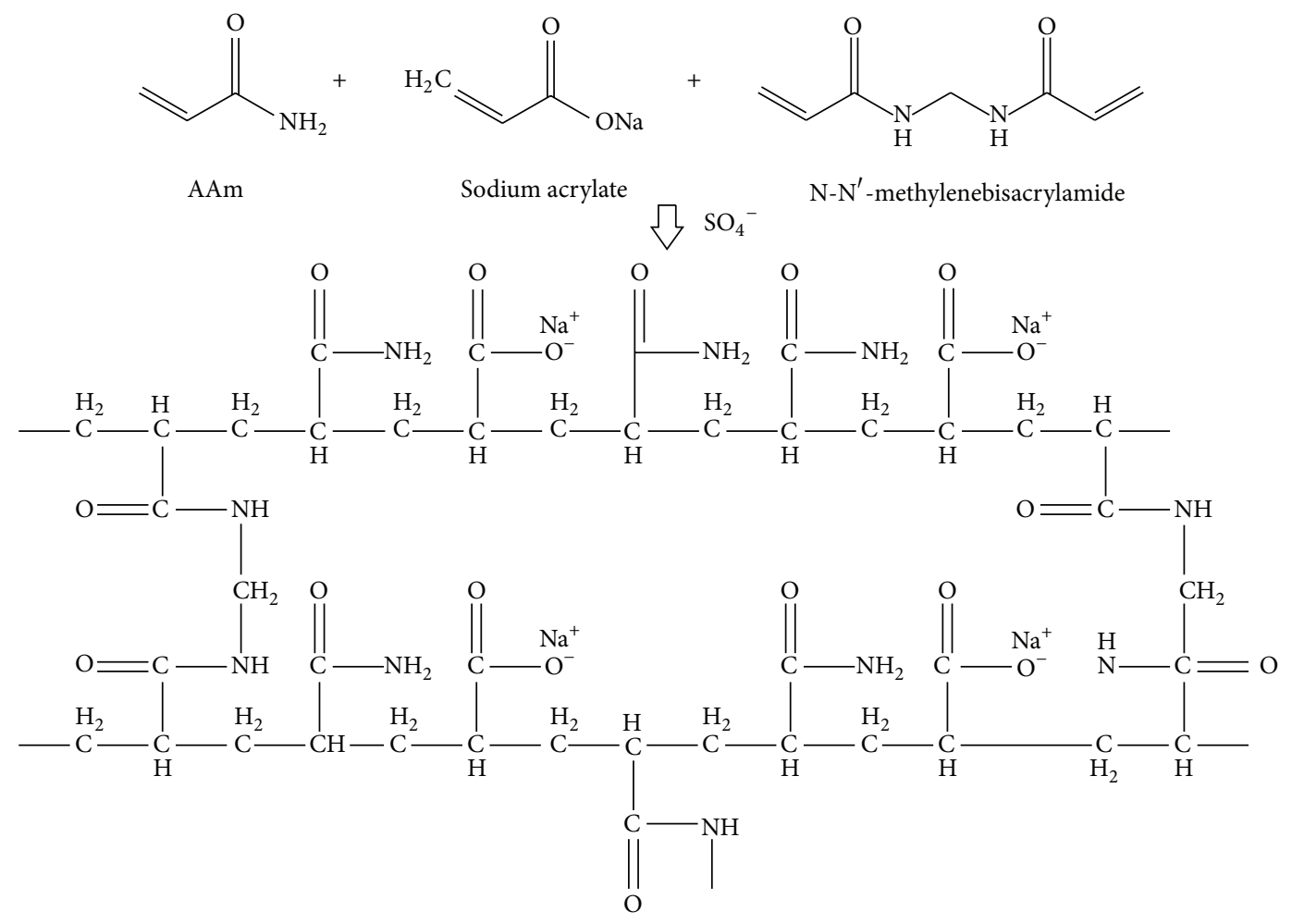

FIgURe 1: Preparation of cross-linked (AAm/SA) hydrogel.

where $S_{t}$ is the swelling content at any time (g/g d.b.) and $S_{t+\Delta t}$ represents the swelling content based on the dry content at “ $t+\Delta t$."

2.6. Diffusion of Water. The most basic law of Fick's is used for the explanation of swelling kinetics and diffusion of the polymeric structures. Swelling kinetics of the polymers can be given by Peppas et al. [27, 28]:

$$
F=\frac{S_{t}}{S_{e}}=k t^{n}
$$

where " $F$ " represents the swelling fraction, " $S_{e}$ " is the equilibrium swelling content of hydrogel, " $n$ " is the diffusion exponential of the solvent, and $k$ is the constant that changes according to the gels network structure.

In order to identify the type of the diffusion, the parameter of " $n$ " must be known. Diffusion exponential of " $n$ " can be estimated from the slope of a line obtained from lnF-lnt graph data of the region where the swelling has not yet reach the equilibrium only $60 \%$ of the solvent mass enters in the structure of gels.

Another important parameter for the examination of the swelling kinetics is the coefficient of diffusion. For the cylindrical type of structures the coefficient of " $D$ " can be found by the equation obtained from the arrangement of Fick's II law and given as [29]

$$
D=\pi r^{2}\left(\frac{k}{4}\right)^{1 / n}
$$

where " $D$ " represents the coefficient of diffusion as " $\mathrm{m}^{2} \mathrm{~s}^{-1}$ " and " $r$ " represents the swollen gels radius as " $m$."

2.7. Activation Energy. The dependence of the diffusivity coefficient on temperature is often given by an Arrhenius type equation [30]:

$$
D=D_{0} \exp \left(\frac{-E_{a}}{R(T+273.15)}\right),
$$

where $D_{0}$ is the preexponential factor of Arrhenius equation $\left(\mathrm{m}^{2} \mathrm{~s}^{-1}\right), E_{a}$ is the activation energy $\left(\mathrm{kJ} \mathrm{mol}^{-1}\right), T$ is temperature of water $\left(\mathrm{K}^{-1}\right)$, and $R$ is the universal gas constant of $8.314 \times 10^{-3}\left(\mathrm{~kJ} \mathrm{~mol}^{-1} \mathrm{~K}^{-1}\right)$.

2.8. Mathematical Modeling of Absorption Kinetics. In this study, the methods that are developed from different researchers, Peleg's model (7), first-order absorption kinetic model (8), and the exponential association equation (9), were used [31-33]. 
Peleg proposed a two-parameter model to describe water absorption by grains [31]:

$$
S=S_{o} \pm \frac{t}{k_{1}+k_{2} t},
$$

where $S_{o}$ is the swelling content at $t=0$ (g/g d.b.), $S$ is the swelling content at any time (g/g d.b.), $t$ is the swelling time (s), $k_{1}$ is the kinetic constant of the model ( $\mathrm{h}(\mathrm{g} \mathrm{d}$.b. $\left.) / \mathrm{g}\right)$, and $k_{2}$ is a characteristic constant of the model ( $\left.\mathrm{g} \mathrm{d} . \mathrm{b}.\right) / \mathrm{g}$ ). In (7), " \pm " becomes "+" if the process is absorption or adsorption and "-" if the process is drying or desorption.

In the first-order absorption kinetic model, the equation used is of the following form $[34,35]$ :

$$
S=S_{e}+\left(S_{o}-S_{e}\right) \exp \left(-k_{R 1} t\right)
$$

where $k_{R 1}$ is the swelling kinetic constant $\left(\mathrm{h}^{-1}\right)$. Consider

$$
S=S_{e}\left[1-\exp \left(-k_{R 2} t\right)\right]
$$

where $k_{R 2}$ is the kinetic constant $\left(\mathrm{h}^{-1}\right)$.

2.9. Statistical Analysis. The statistical analysis of experimental data was determined using Statistica 6.0 software (Statsoft Inc., Tulsa, OK), which is based on the Levenberg-Marquardt algorithm. The three criteria $\left(R^{2}, \chi^{2}\right.$, and RMSE) of statistical analysis have been used to evaluate the adjustment of the experimental data to the different models. $\chi^{2}$ and RMSE parameters can be calculated as

$$
\begin{aligned}
\chi^{2} & =\frac{\sum_{i=1}^{N}\left(\mathrm{SR}_{\mathrm{exp}, i}-\mathrm{SR}_{\mathrm{pre}, i}\right)^{2}}{N-z}, \\
\mathrm{RMSE} & =\left[\frac{1}{N} \sum_{i=1}^{N}\left(\mathrm{SR}_{\mathrm{pre}, i}-\mathrm{SR}_{\mathrm{exp}, i}\right)^{2}\right]^{1 / 2},
\end{aligned}
$$

where $\mathrm{SR}_{\exp , I}$ and $\mathrm{SR}_{\text {pre }, I}$ are the experimental and predicted dimensionless SR (swelling rate), respectively, $N$ is the number of data values, and $z$ is the number of constants of the models. The best model describing the swelling characteristics of hydrogels was chosen as the one with the highest $R^{2}$ and the least $\chi^{2}$ and RMSE [36].

\section{Results and Discussion}

3.1. Swelling Curves. Swelling is one of the important parameters in the characterization of the cross-linked hydrogels. Swelling tests at the temperatures of 25,40 , and $60^{\circ} \mathrm{C}$ were conducted using the hydrogel of acrylamide (AAm)/sodium acrylate (SA).

The starting water contents of the hydrogels were determined as $0.0078 \mathrm{~g}$ water/g dry hydrogel. One gram of hydrogels on the dry basis was weighed and put inside the beaker with the $100 \mathrm{~mL}$ distilled water inside for swelling. Temperatures were controlled with the Heidolph magnetic stirrer and heater with temperature controller unit. The initial time $(t=0)$ is set and the weights of the hydrogels were

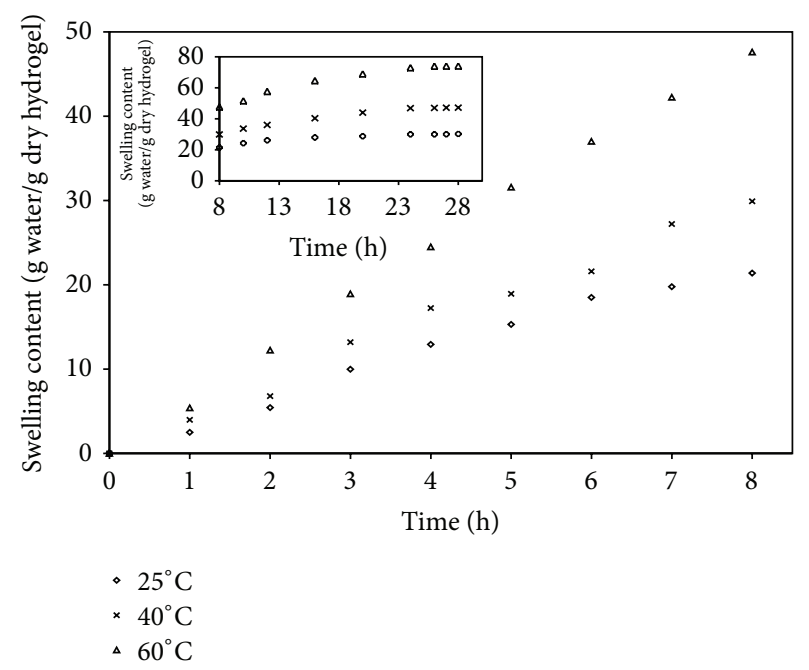

FIgURE 2: Swelling of hydrogel as a function of time at different temperatures.

weighted after taking the surface moisture at specific time intervals. Then using the weights the swelling kinetics were investigated.

From the results obtained the hydrogel swelling came to equilibrium value at the end of 28 hours. The swelling equilibrium values for the hydrogel were found as $30.19,47.18$, and $74.07 \mathrm{~g}$ water/g dry hydrogel for the temperatures of 25 , 40 , and $60^{\circ} \mathrm{C}$, respectively.

The swelling content, $S$ (g/g d.b.), was calculated using (2). From these values, the $S$ - $t$ graph was drawn and the swelling isotherms were constructed, shown in Figure 2.

The swelling content of the hydrogels was higher at the first 8 hours so the kinetic studies were conducted at these values. As seen from Figure 2, the hydrogels swelling contents at the three different temperatures are very high at the first 8 hours.

After the 8th hour, the swelling content was gradually increased. Since the kinetic studies were done within the first 8 hours, the other swelling content values were given in the small graph inside the Figure 2.

From Figure 2, the swelling content values of 21.4, 29.9, and $47.6 \mathrm{~g}$ water/g dry hydrogel were seen at the different temperatures of 25,40 , and $60^{\circ} \mathrm{C}$, respectively.

The hydrogel swelling content increases with increasing temperatures as seen from Figure 2. The swelling value at $60^{\circ} \mathrm{C}$ is twice as big as the value at $25^{\circ} \mathrm{C}$. It is possible to say that the $\mathrm{H}$-bonds inside the hydrogels were broken due to temperature rise and thus increase the amount of swelling. Also the increase in swelling value with increasing temperature of the hydrogel might be caused by the increase in thermal mobility of polymer molecules inside the hydrogels [37].

Uzum et al. [38] synthesized acrylamide (AAm)/(SA) of sodium acrylate hydrogels from two different types of cross-linkers, by changing the sodium acrylate monomer concentration. They investigated the swelling ratio change 


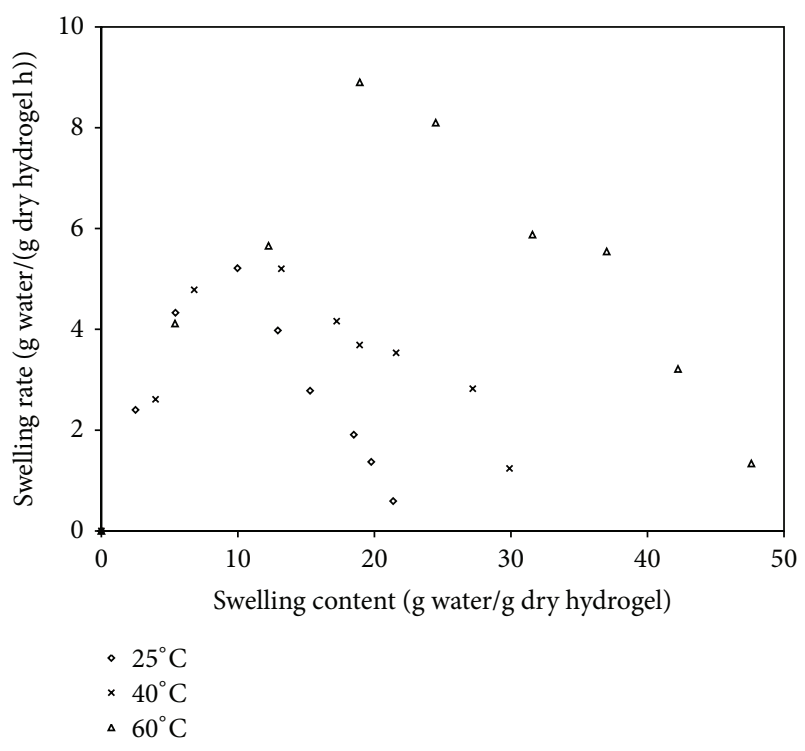

FIGURE 3: Swelling rate curves for hydrogel at different temperatures.

of the synthesized hydrogels by changing the cross linker types and of sodium acrylate monomer concentrations. They reported that hydrogels swelling ratio is increased with the increasing concentrations of sodium acrylate monomer and cross-linkers.

Mohan et al. [39] synthesized a superabsorbent copolymer acrylamide-sodium methacrylate and concluded that the copolymers swelling ratios are increased by the increasing sodium methacrylate concentration.

Figure 3 shows the hydrogels swelling rate change according to the swelling content. As seen in Figure 3, the swelling rates and swelling content are increased with the increasing temperature. From the experiments that are done in the $60^{\circ} \mathrm{C}$ temperature, the maximum swelling content is found as $18.93 \mathrm{~g}$ water/g dry hydrogel that corresponds to a swelling rate of $8.9 \mathrm{~g}$ water/g dry hydrogel h. Simply in the $40^{\circ} \mathrm{C}$ and $25^{\circ} \mathrm{C}$ temperature the maximum swelling contents are found as 13.20 and $9.97 \mathrm{~g}$ water/g dry hydrogel that correspond to a swelling rate of 5.22 and $5.21 \mathrm{~g}$ water/g dry hydrogel h, respectively.

3.2. Calculation of Diffusion Coefficients. Fick's laws are the common laws used to explain water diffusion into the dried hydrogel and its diffusion type [40].

The mechanisms of water diffusion into the swelled hydrogel were investigated by (4). The plots of $\ln F$ versus $\ln t$ were obtained through the logarithmic form of (4), and these graphs are given in Figure 4. The values of $n, k$ and regression coefficients were calculated from the slopes and the intercepts of the plots of $\ln F$ against $\ln t$, respectively, and are given in Table 1.

Equation (4) is valid for the first $60 \%$ of the fractional uptake. The Fick's diffusion transport is defined by $\mathrm{n}$ and this value is used for determining the diffusion type [41]. Fickian diffusion and Case II transport are defined by $n$ values of 0.5 and 1.0, respectively. The calculated swelling exponent values

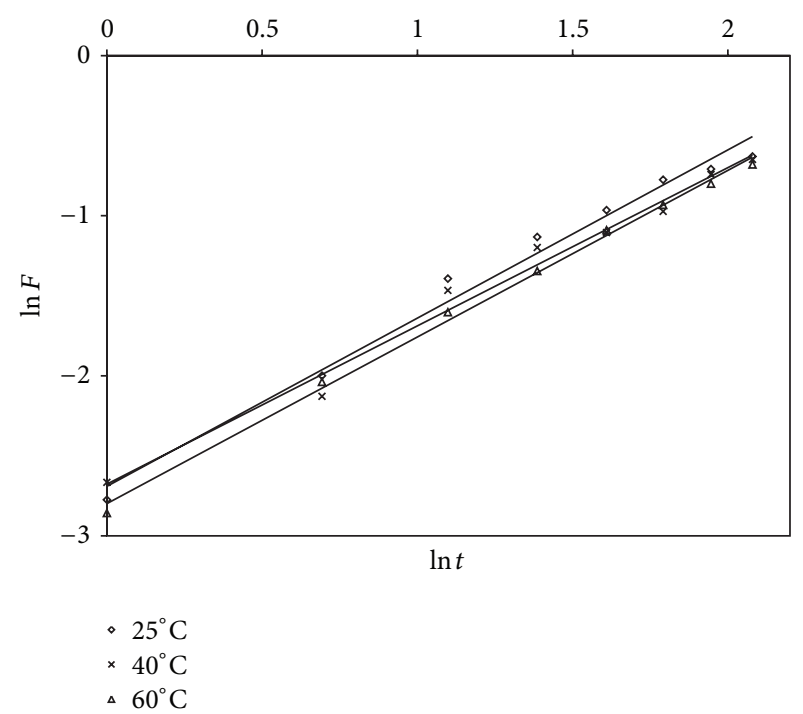

FIGURE 4: Swelling kinetic curves for hydrogel at different temperatures.

(n) are in between 0.938 and 0.997 . These swelling exponent values indicate that the transport of all super absorbent polymers was of non-Fickian character. The values for $k$ and $R^{2}$ varied between $6.15-6.83$ and $0.984-0.997$ for all the experimental conditions, respectively. Diffusion coefficient $(D)$ is one of the major parameters to determine the swelling characterization of the hydrogel, and it is calculated by using (5). The values of diffusion coefficient determined for the hydrogel are listed in Table 1. As seen in Table 1, the diffusion coefficients increase by increasing temperature. The diffusion coefficient was obtained with the dried hydrogel as $1.81 \times$ $10^{-7}, 2.07 \times 10^{-7}$, and $2.97 \times 10^{-7} \mathrm{~m}^{2} \mathrm{~s}^{-1}$ at 25,40 , and $60^{\circ} \mathrm{C}$, respectively.

3.3. Calculation of the Activation Energy. The calculated diffusivities were plotted as a function of the absolute waterswelling temperature (Figure 5). The plot was found to be essentially a straight line in the range of temperatures investigated, indicating Arrhenius dependence. From the intercept of the straight line described by the Arrhenius equation, $D_{0}$ is calculated as $2.05 \times 10^{-5} \mathrm{~m}^{2} \mathrm{~s}^{-1}$. Using (6) the activation energies are found as $3.56,3.71$, and $3.86 \mathrm{~kJ} \mathrm{~mol}^{-1}$ at 25,40 , and $60^{\circ} \mathrm{C}$, respectively.

3.4. Evaluation of the Models. To describe the swelling kinetics of hydrogel on different temperatures $(25,40$, and $60^{\circ} \mathrm{C}$ ), three empirical models, namely, Peleg's, first-order, and exponential association equation, are used, and all of them provided a good agreement with the experimental data. The constants, $R^{2}, \chi^{2}$, and RMSE values of the models are estimated and given in Table 2.

As it can be seen from Table 2 , the kinetic rate constant $k_{1}$ and the characteristic constant $k_{2}$ of the Peleg's model and the scale parameter $\left(k_{R 1}\right.$ and $\left.k_{R 2}\right)$ of first-order and exponential association models are changed inversely proportional to 


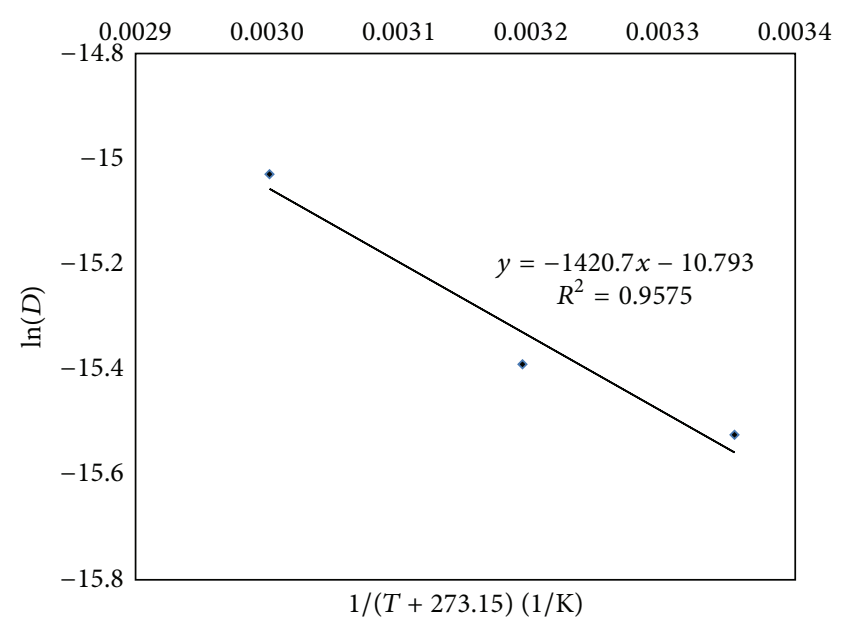

FIGURE 5: Arrhenius-type relationship between effective diffusivity coefficient and temperature.

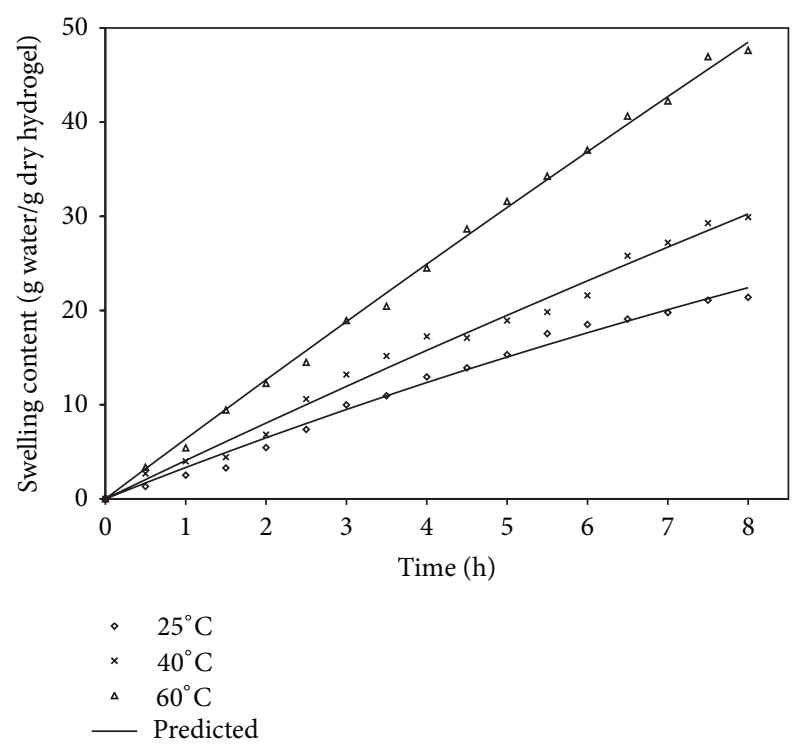

FIGURE 6: Hydrogel swelling content values for both experimental and predicted values based upon to the exponential association model.

TABLE 1: Values of swelling coefficients of dried hydrogel.

\begin{tabular}{lccc}
\hline Coefficients & \multicolumn{3}{c}{ Swelling temperature $\left({ }^{\circ} \mathrm{C}\right)$} \\
\hline$n$ & 25 & 40 & 60 \\
$k \times 10^{2}$ & 0.997 & 0.938 & 0.981 \\
$R^{2}$ & 6.83 & 6.93 & 6.15 \\
$D \times 10^{7}$ & 0.984 & 0.985 & 0.997 \\
\hline
\end{tabular}

the temperature. In other words, it can also be seen from the models that $k_{1}, k_{2}, k_{R 1}$, and $k_{R 2}$ values are reduced by the increase in temperature.

The data obtained from the Peleg model showed that the least $k_{1}$ and $k_{2}$ values are obtained at $60^{\circ} \mathrm{C}$ temperature.
The $k_{1}$ and $k_{2}$ values obtained are found as 0.293712 and 0.007808 at $25^{\circ} \mathrm{C}, 0.243454$ and 0.002637 at $40^{\circ} \mathrm{C}$, and 0.160218 and 0.000409 at $60^{\circ} \mathrm{C}$. Also, Maskan [42] and Solomon [43] have reported that high water absorption capacity is correlated with the low $k_{1}$ and $k_{2}$ values.

From the investigation of $R^{2}, \chi^{2}$, and RMSE, it was seen that the $R^{2}$ value is almost as "1"; RMSE and $\chi^{2}$ are the minimum at the model of exponential association. Also the values given in Table 2 are very close to each other. At the mentioned temperatures the calculated values by the exponential association fit the experimental values at best. The $R^{2}$ values were calculated as $0.9894,0.9940$, and 0.9988 at the temperatures of 25,40 , and $60^{\circ} \mathrm{C}$, respectively.

In Figure 6, the experimental values are compared with the predicted values obtained from the exponential association model for the first 8 hours of hydration.

As seen from Figure 6, the predicted swelling values for the hydrogel based upon the exponential association model are in good agreement with the experimental values.

\section{Conclusions}

In this study, the acrylamide-sodium acrylate hydrogel was synthesized and the effect of temperature on the swelling kinetics of hydrogel was investigated. The swelling equilibrium values for the hydrogel were found as $30.19,47.18$, and $74.07 \mathrm{~g}$ water/g dry hydrogel for the temperatures of 25,40 , and $60^{\circ} \mathrm{C}$, respectively. As the temperature increased hydrogels swelling content and swelling rate were also increased.

The physical properties of the hydrogel (LCST and swelling) and thermal properties depend on the properties and amount of the monomers used in the synthesis. Therefore, a hydrogel can be arranged to absorb high water capacities by changing the monomer properties (variation and amount). In this study synthesized hydrogel's LCST is found as $60^{\circ} \mathrm{C}$. At that temperature the water absorption capacity of the hydrogel increases. After the temperature of $60^{\circ} \mathrm{C}$ hydrogels have shrunk by giving their absorbed water.

The values of calculated diffusion coefficients ranged from $1.81 \times 10^{-7}$ to $2.97 \times 10^{-7} \mathrm{~m}^{2} \mathrm{~s}^{-1}$. The swelling rate and effective diffusivity increase with air temperature increases (consequently swelling content increased), where, in the study of Aktas et al. [24], diffusion constants were found to be in the range of $0.37 \times 10^{-9}-4.00 \times 10^{-9} \mathrm{~m}^{2} \mathrm{~s}^{-1}$, which are considerably smaller than our study. The difference between literature values and our study most probably originates from the solvents at which the gels were swelled.

Temperature dependence of the diffusivity coefficients was described by Arrhenius-type relationship. The activation energies are found as $3.56,3.71$, and $3.86 \mathrm{~kJ} \mathrm{~mol}^{-1}$ at 25,40 , and $60^{\circ} \mathrm{C}$, respectively.

In order to determine the water content uptake as a function of swelling time, three different models were examined, and all these models provided a good agreement with the experimental data; however, the exponential association equation model was chosen as the appropriate model to represent the swelling kinetics of hydrogels. 
TABLE 2: Estimated parameters of the models used for various swelling temperatures.

\begin{tabular}{|c|c|c|c|c|c|}
\hline \multicolumn{6}{|c|}{ Peleg's model } \\
\hline Temperature $\left({ }^{\circ} \mathrm{C}\right)$ & $k_{1}$ & $k_{2}$ & $R^{2}$ & RMSE & $x^{2}$ \\
\hline 25 & 0.293712 & 0.007808 & 0.9889 & 2.48790 & 0.63632 \\
\hline 40 & 0.243454 & 0.002637 & 0.9894 & 3.62427 & 1.16706 \\
\hline 60 & 0.160218 & 0.000409 & 0.9988 & 2.46038 & 0.58306 \\
\hline \multicolumn{6}{|c|}{ First-order rehydration kinetic model } \\
\hline Temperature $\left({ }^{\circ} \mathrm{C}\right)$ & $k_{R 1}$ & & & RMSE & $\chi^{2}$ \\
\hline 25 & 0.0486 & & & 2.44348 & 0.58668 \\
\hline 40 & 0.0288 & & & 3.62423 & 1.09429 \\
\hline 60 & 0.0136 & & & 2.46411 & 0.58774 \\
\hline \multicolumn{6}{|c|}{ Exponential association model } \\
\hline Temperature $\left({ }^{\circ} \mathrm{C}\right)$ & $k_{R 2}$ & & & RMSE & $x^{2}$ \\
\hline 25 & 0.0506 & & & 2.38588 & 0.56817 \\
\hline 40 & 0.0310 & & & 3.60784 & 1.09205 \\
\hline 60 & 0.0135 & & & 2.46025 & 0.58046 \\
\hline
\end{tabular}

\section{Conflict of Interests}

The authors declare that there is no conflict of interests regarding the publication of this paper.

\section{References}

[1] K. Makuuchi, "Critical review of radiation processing of hydrogel and polysaccharide," Radiation Physics and Chemistry, vol. 79, no. 3, pp. 267-271, 2010.

[2] C. Chang, B. Duan, J. Cai, and L. Zhang, "Superabsorbent hydrogels based on cellulose for smart swelling and controllable delivery," European Polymer Journal, vol. 46, no. 1, pp. 92-100, 2010.

[3] H. Ferfera-Harrar, N. Aiouaz, N. Dairi, and A. S. Hadj-Hamou, "Preparation of chitosan-g-poly(acrylamide)/montmorillonite superabsorbent polymer composites: studies on swelling, thermal, and antibacterial properties," Journal of Applied Polymer Science, vol. 131, no. 1, p. 14, 2014.

[4] B. Jeong, Y. H. Bae, and S. W. Kim, "Drug release from biodegradable injectable thermosensitive hydrogel of PEGPLGA-PEG triblock copolymers," Journal of Controlled Release, vol. 63, no. 1-2, pp. 155-163, 2000.

[5] S. K. Bajpai and S. Singh, "Analysis of swelling behavior of poly(methacrylamide-co-methacrylic acid) hydrogels and effect of synthesis conditions on water uptake," Reactive and Functional Polymers, vol. 66, no. 4, pp. 431-440, 2006.

[6] G. Frutos, A. Prior-Cabanillas, R. París, and I. QuijadaGarrido, "A novel controlled drug delivery system based on pH-responsive hydrogels included in soft gelatin capsules," Acta Biomaterialia, vol. 6, no. 12, pp. 4650-4656, 2010.

[7] N. R. Gupta, P. P. Ghute, and M. V. Badiger, "Synthesis and characterization of thermo-sensitive graft copolymer of carboxymethyl guar and poly(N-isopropylacrylamide)," Carbohydrate Polymers, vol. 83, no. 1, pp. 74-80, 2011.

[8] A. K. Bajpai and M. Shrivastava, "Dynamic swelling behavior of polyacrylamide based three component hydrogels," Journal of Macromolecular Science A: Pure and Applied Chemistry, vol. 37, no. 9, pp. 1069-1088, 2000.

[9] M. Sivanantham and B. V. R. Tata, "Swelling/deswelling of polyacrylamide gels in aqueous $\mathrm{NaCl}$ solution: light scattering and macroscopic swelling study," Pramana, vol. 79, no. 3, pp. 457-469, 2012.

[10] A. Vashist, Y. K. Gupta, and S. Ahmad, "Interpenetrating biopolymer network based hydrogels for an effective drug delivery system," Carbohydrate Polymers, vol. 87, no. 2, pp. 14331439, 2012.

[11] X. F. Sun, Z. Jing, and G. Wang, "Preparation and swelling behaviors of porous hemicellulose-g-polyacrylamide hydrogels," Journal of Applied Polymer Science, vol. 128, no. 3, pp. 18611870, 2013.

[12] M. Bulut, Makrogözenekli poli (akrilamit) hidrojellerinin hazırlanması ve farklı ortamlardaki şişme davranışlarının incelenmesi [M.S. thesis], Graduate School of Natural and Applied Sciences, Gazi University, Ankara, Turkey, 2005.

[13] M. E. Byrne, K. Park, and N. A. Peppas, "Molecular imprinting within hydrogels," Advanced Drug Delivery Reviews, vol. 54, no. 1, pp. 149-161, 2002.

[14] L. E. Bromberg and E. S. Ron, “Temperature-responsive gels and thermogelling polymer matrices for protein and peptide delivery," Medicine, vol. 39, no. 2, pp. 19-24, 2003.

[15] J. E. Elliott, M. MacDonald, J. Nie, and C. N. Bowman, "Structure and swelling of poly(acrylic acid) hydrogels: effect of $\mathrm{pH}$, ionic strength, and dilution on the crosslinked polymer structure," Polymer, vol. 45, no. 5, pp. 1503-1510, 2004.

[16] D. Saraydin, E. Karadag, Y. Isikver et al., "The influence of preparation methods on the swelling and network properties of acrylamide hydrogels with crosslinkers," Journal of Macromolecular Science A, vol. 41, no. 4, pp. 421-433, 2004.

[17] K. Kabiri, H. Omidian, S. A. Hashemi, and M. J. ZohuriaanMehr, "Synthesis of fast-swelling superabsorbent hydrogels: Effect of crosslinker type and concentration on porosity and absorption rate," European Polymer Journal, vol. 39, no. 7, pp. 1341-1348, 2003.

[18] W. M. Thomas and D. Wei Wang, "Acrylamide polymers," in Encyclopedia of Polymer Science and Engineering, H. F. Mark and N. M. Bikales, Eds., vol. 1, pp. 169-211, John Wiley \& Sons, New York, NY, USA, 1964.

[19] E. Karadağ and D. Saraydin, "Swelling studies of super water retainer acrylamide/crotonic acid hydrogels crosslinked by trimethylolpropane triacrylate and 1,4-butanediol dimethacrylate," Polymer Bulletin, vol. 48, no. 3, pp. 299-307, 2002. 
[20] E. Karadağ, O. B. Üzüm, and D. Saraydin, "Swelling equilibria and dye adsorption studies of chemically crosslinked superabsorbent acrylamide/maleic acid hydrogels," European Polymer Journal, vol. 38, no. 11, pp. 2133-2141, 2002.

[21] T. Tanaka and D. J. Filmore, "Kinetics of swelling of gels," The Journal of Chemical Physics, vol. 70, no. 3, p. 1214, 1979.

[22] Y. Li and T. Tanaka, "Kinetics of swelling and shrinking of gels," The Journal of Chemical Physics, vol. 92, no. 2, p. 1365, 1990.

[23] D. K. Aktas, G. A. Evingur, and O. Pekcan, "Study on swelling of hydrogels (PAAm) at various temperatures by using fluorescence technique," Journal of Materials Science, vol. 42, no. 20, pp. 8481-8488, 2007.

[24] D. K. Aktas, G. A. Evingur, and O. Pekcan, "A fluorescence study on swelling of hydrogels (PAAm) at various cross-linker contents," Advances in Polymer Technology, vol. 28, no. 4, pp. 215-223, 2009.

[25] K. M. Raju, M. P. Raju, and Y. M. Mohan, "Synthesis and swelling behavior of superabsorbent polymeric materials," International Journal of Polymeric Materials and Polymeric Biomaterials, vol. 53, no. 5, pp. 419-429, 2004.

[26] O. Ismail, A. S. Kipcak, and S. Piskin, "Modeling of absorption kinetics of poly(acrylamide) hydrogels crosslinked by EGDMA and PEGDMAs," Research on Chemical Intermediates, vol. 39, no. 3, pp. 907-919, 2013.

[27] N. A. Peppas, P. Bures, W. Leobandung, and H. Ichikawa, "Hydrogels in pharmaceutical formulations," European Journal of Pharmaceutics and Biopharmaceutics, vol. 50, pp. 27-46, 2000.

[28] R. Zarzycki, Z. Modrzejewska, and K. Nawrotek, "Drug release from hydrogel matrices," Ecological Chemistry and Engineering S, vol. 17, no. 2, pp. 117-136, 2010.

[29] R. Dengre, M. Bajpai, and S. K. Bajpai, "Release of vitamin $B_{12}$ from poly(N-vinyl-2-pyrrolidone)-crosslinked polyacrylamide hydrogels: a kinetic study," Journal of Applied Polymer Science, vol. 76, pp. 1706-1714, 2000.

[30] M. Böhning, N. Hao, and A. Schönhals, "Correlation of activation energies of gas diffusivity and local matrix mobility in polycarbonate/POSS nanocomposites," Journal of Polymer Science B: Polymer Physics, vol. 51, no. 22, pp. 1593-1597, 2013.

[31] M. Peleg, "An empirical model for the description of moisture sorption curves," Journal of Food Science, vol. 53, no. 4, pp. 12161217, 1988.

[32] D. K. Apar, E. Demirhan, B. Özbek, and G. Dadali, "Rehydration kinetics of microwave-dried okras as affected by drying conditions," Journal of Food Processing and Preservation, vol. 33, no. 5, pp. 618-634, 2009.

[33] M. Noshad, M. Mohebbi, F. Shahidi, and S. A. Mortazavi, "Kinetic modeling of rehydration in air-dried quinces pretreated with osmotic dehydration and ultrasonic," Journal of Food Processing and Preservation, vol. 36, no. 5, pp. 383-392, 2012.

[34] K. G. Kaptso, Y. N. Njintang, A. E. Komnek, J. Hounhouigan, J. Scher, and C. M. F. Mbofung, "Physical properties and rehydration kinetics of two varieties of cowpea (Vigna unguiculata) and bambara groundnuts (Voandzeia subterranea) seeds," Journal of Food Engineering, vol. 86, no. 1, pp. 91-99, 2008.

[35] K. Górnicki, A. Kaleta, R. Winiczenko et al., "Chapter 16: some remarks on modelling of mass transfer kinetics during rehydration of dried fruits and vegetables engineering," in Mass Transfer-Advances in Sustainable Energy and Environment Oriented Numerical Modeling, H. Nakajima, Ed., 2013.
[36] A. Kaleta and K. Górnicki, "Some remarks on evaluation of drying models of red beet particles," Energy Conversion and Management, vol. 51, no. 12, pp. 2967-2978, 2010.

[37] D. E. Rodríguez, J. Romero-García, E. Ramírez-Vargas, A. S. Ledezma-Pérez, and E. Arías-Marín, "Synthesis and swelling characteristics of semi-interpenetrating polymer network hydrogels composed of poly(acrylamide) and poly $(\gamma$-glutamic acid)," Materials Letters, vol. 60, no. 11, pp. 1390-1393, 2006.

[38] O. B. Uzum, S. Kundakci, H. B. Durukan, and E. Karadag, "Swelling and dye sorption studies of AAm/SA hydrogels crosslinked by glutaraldehyde and divinylbenzene," Journal of Applied Polymer Science, vol. 105, pp. 2646-2654, 2007.

[39] Y. M. Mohan, P. S. K. Murthy, and K. M. Raju, "Synthesis, characterization and effect of reaction parameters on swelling properties of acrylamide-sodium methacrylate superabsorbent copolymers," Reactive and Functional Polymers, vol. 63, no. 1, pp. 11-26, 2005.

[40] M. T. am Ende and N. A. Peppas, "Transport of ionizable drugs and proteins in crosslinked poly(acrylic acid) and poly(acrylic acid-co-2-hydroxyethyl methacrylate) hydrogels. II. Diffusion and release studies," Journal of Controlled Release, vol. 48, no. 1, pp. 47-56, 1997.

[41] N. A. Peppas and L. Brannon-Peppas, "Water diffusion and sorption in amorphous macromolecular systems and foods," Journal of Food Engineering, vol. 22, no. 1-4, pp. 189-210, 1994.

[42] M. Maskan, "Effect of processing on hydration kinetics of three wheat products of the same variety," Journal of Food Engineering, vol. 52, no. 4, pp. 337-341, 2002.

[43] W. K. Solomon, "Hydration kinetics of lupin (Lupinus albus) seeds," Journal of Food Process Engineering, vol. 30, no. 1, pp. 119130, 2007. 

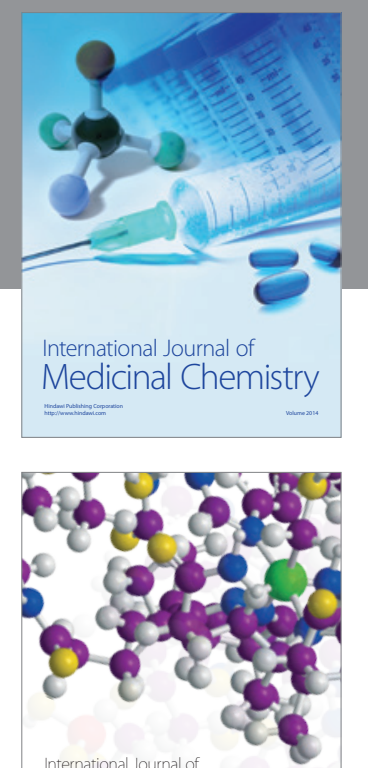

\section{Carbohydrate} Chemistry

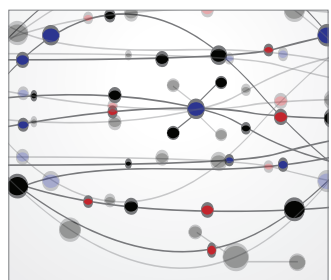

The Scientific World Journal
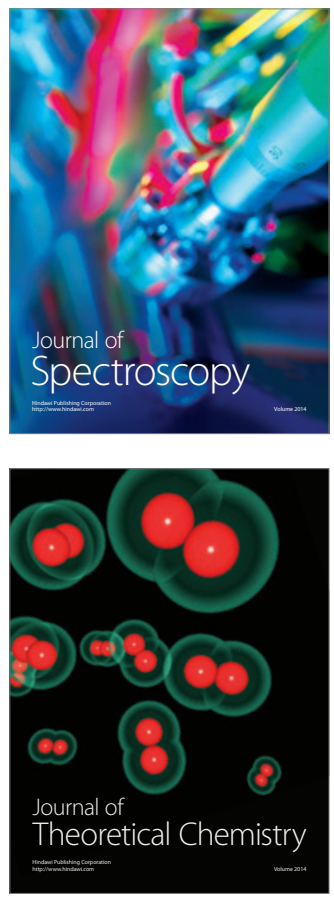
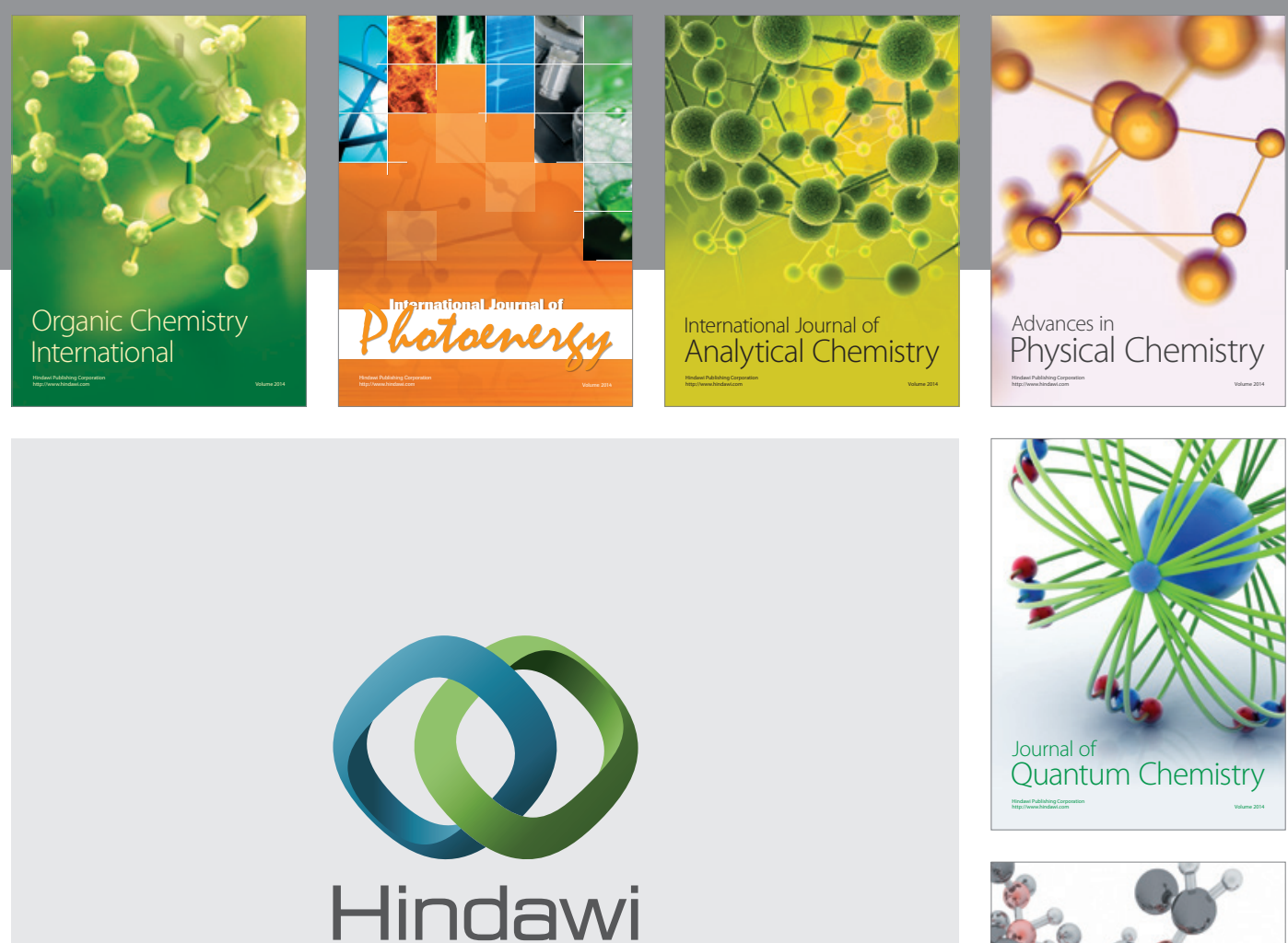

Submit your manuscripts at

http://www.hindawi.com

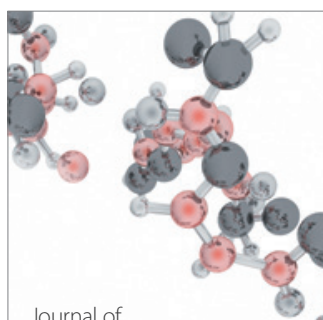

Analytical Methods

in Chemistry

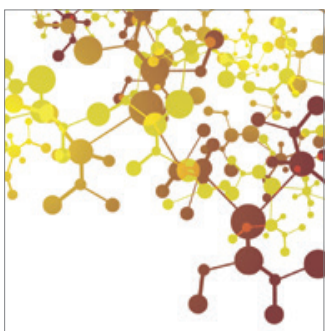

Journal of

Applied Chemistry

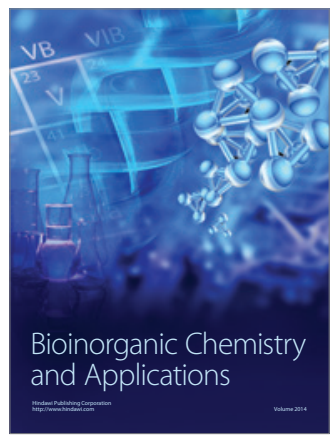

Inorganic Chemistry
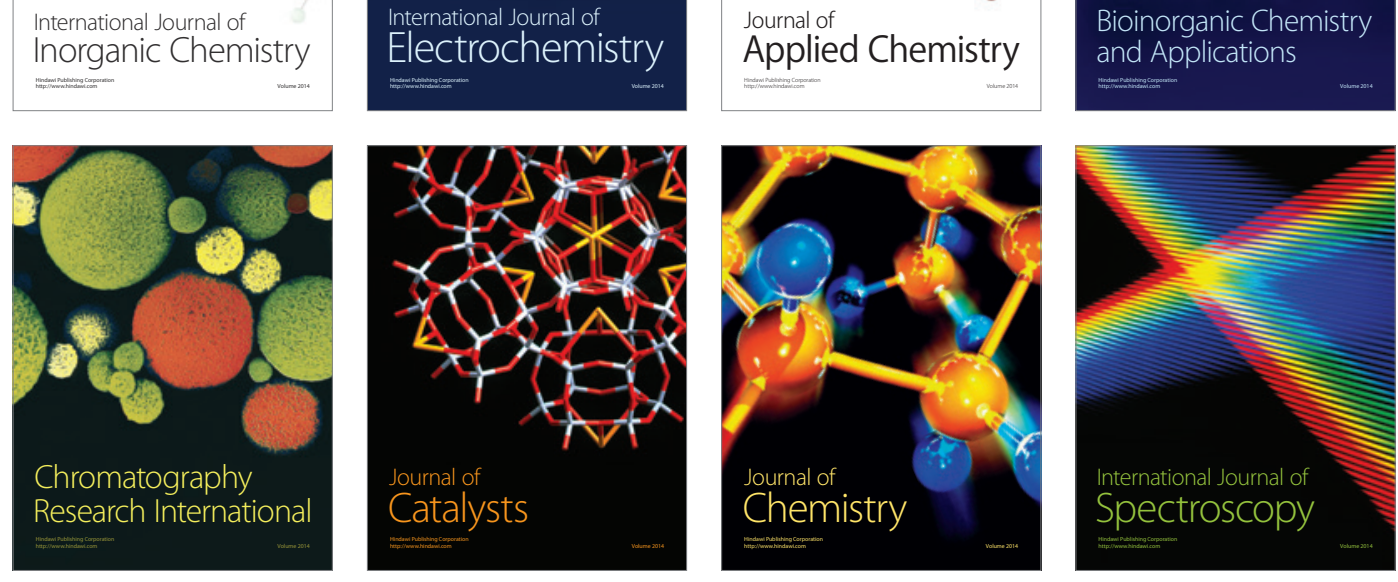